than the neighbouring Kenya. The Somali wild ass, hunted from jeeps and landrovers, is on the verge of extinction, and Swayne's hartebeest, once exceedingly common, has gone.

The system of open seasons for kangaroos in New South Wales was last year replaced by a licensing system, thanks to hard campaigning by conservationists and some heated controversy in the press about the slaughter of kangaroos. The system of open seasons, by

Relief
for the
Kangaroos
which one or more of the five species could be killed for periods up to twelve months over an entire Pasture Protection District, had come to be regarded as a regular event and even as a right, not only by farmers and landowners whose crops suffered damage and who wanted to exterminate "the pest ", but also commercial interests, especially the kangaroo meat trade, and sporting shooters, the last inevitably including irresponsible types who shot at anything, including protected birds and mammals. Most landowners, says the report of the Fauna Protection Panel, believe that conservation is nothing but sentiment, and " find the suggestion that wild animals as a basis for research are actually of value to agriculture too ridiculous for words". The licensing system reduces the kangaroo populations where necessary, puts the responsibility on the landowner, and not only reduces the activities of the casual shooter but also gives the Field Officers of the Fauna Panel much useful information about population distribution and fluctuations.

Conservationists were rather startled to learn that President Suekarno had presented a pair of Komodo dragons to Mr. Robert Kennedy when he recently visited Indonesia. The Komodo dragon is described by the Survival Service Commission as "threatened with Report on extermination ", with a total population of not more the Komodo than 300 . But the FPS has been assured by the Director Dragon of the Indonesian Forest Service, Mr. Hasan Basjaroedin, that the Komodo dragon's numbers are increasing; he puts the numbers at the end of 1962 at 400-500. In 1963 a number of juveniles were seen, including ten to twenty at one place.

\title{
Frank Simon Collier
}

The death occurred on February 6th, 1964, of Frank Simon Collier, C.M.G., C.B.E., a valued member of the Society's Council from 1953 to 1957. A Forest Officer in Nigeria, then Chief Conservator, he became Adviser to the Secretary of State for the Colonies, and travelled widely. His work and intense interest in animals and birds gave him a knowledge of the larger West African fauna which remains unequalled. A remarkable visual memory and a natural facility with pencil and brush enabled him to record, delightfully and vividly, the birds and beasts which gave him such pleasure. In Nigeria his efforts to create a workable set of wildlife conservation laws unfortunately came to nothing, but it strikes the keynote of his life's work. His value to the Council lay both in his wide acquaintance with the world fauna and his quick recognition of what was practicable.

D. R. ROSEVEAR. 